\title{
Stages of granulovacuolar degeneration: their relation to Alzheimer's disease and chronic stress response
}

\author{
Dietmar Rudolf Thal $\cdot$ Kelly Del Tredici • Albert C. Ludolph • \\ Jeroen J. M. Hoozemans • Annemieke J. Rozemuller • \\ Heiko Braak • Uwe Knippschild
}

Received: 9 March 2011 /Revised: 5 September 2011/Accepted: 5 September 2011/Published online: 21 September 2011

(C) Springer-Verlag 2011

\begin{abstract}
Granulovacuolar degeneration (GVD) is characterized by the presence of vacuolar cytoplasmic lesions in nerve cells of the medial temporal lobe. These changes occur in older non-diseased individuals as well as in patients with Alzheimer's disease (AD), progressive supranuclear palsy (PSP), Pick's, sporadic Parkinson's (PD), and Guam diseases. We stained representative paraffin sections from all parts of the brain with anti-pTDP43, anti-CK $1 \delta$ or anti-CK $1 \varepsilon$ from 14 non-demented elderly, 19 AD, 17 non-AD tauopathy, 9 sporadic PD, and 5 TDP43proteinopathy [amyotrophic lateral sclerosis (ALS) and frontotemporal lobar degeneration (FTLD)] cases. Our results showed five stages of GVD based on its distribution pattern: GVD began in the hippocampal subfields CA1, $\mathrm{CA} 2$, and the subiculum. In a second stage, entorhinal cortex, and CA4 neurons exhibited GVD. Additional neurons were involved in the temporal neocortex in stage 3, whereas the affection of the amygdala and/or the hypothalamus marked stage 4. A fifth and final stage was characterized by additional GVD in the cingulate cortex and occasionally in the frontal and parietal cortices as well as in
\end{abstract}

\section{R. Thal $(\bowtie)$}

Laboratory of Neuropathology, Institute of Pathology, Center for Clinical Research, University of Ulm, Ulm, Germany e-mail: Dietmar.Thal@uni-ulm.de

K. Del Tredici · A. C. Ludolph · H. Braak

Department of Neurology, University of Ulm, Ulm, Germany

J. J. M. Hoozemans · A. J. Rozemuller

Department of Pathology, VU University Medical Center,

Amsterdam, The Netherlands

U. Knippschild

Department of General, Visceral, and Transplantation Surgery,

University of Ulm, Ulm, Germany the oral raphe and pedunculopontine tegmental nuclei. The GVD stages correlated with neurofibrillary tangle stages, Consortium to Establish a Registry for AD (CERAD) scores for neuritic plaque pathology, amyloid $\beta$-protein deposition phases, cerebral amyloid angiopathy stages, and clinical dementia rating (CDR) scores. No associations were seen between GVD stage and the presence of non-AD tauopathies, PD, ALS, or FTLD cases. In conclusion, GVD affects neurons in a hierarchical sequence that allows the distinction of five stages. The topographic distribution of GVD restricted to regions involved in response to chronic stress could indicate a link between GVD and chronically stressful influences. Moreover, the association of the GVD stages with those of AD-related pathology but not with other neurodegenerative disorders points to a possible role of GVD and the response to chronic stress in the pathogenesis of $\mathrm{AD}$.

Keywords Granulovacuolar degeneration .

Amyloid $\beta$-protein $\cdot$ Neurofibrillary tangles $\cdot \tau$-Protein . Dementia - Argyrophilic grain disease - Circadian clock · Chronic stress-response $\cdot$ pTDP43

\section{Introduction}

Granulovacuolar degeneration (GVD) is marked by the presence of vacuolar changes in the cytoplasm of neurons of the medial temporal lobe (MTL) [4, 36, 49]. GVD lesions have also been described in the neocortex, hypothalamus, amygdala, and in the paramedian nuclei of the midbrain [37]. GVD-affected neurons were more frequently seen in Alzheimer's disease (AD) cases than in controls [3, 14]. Other authors did not find such a correlation between GVD and $\mathrm{AD}$ when comparing $\mathrm{AD}$ cases with non-demented 
cases with AD-related pathology [46]. Down syndrome cases also exhibited GVD in age-related amounts rather than in relation to AD-related neurofibrillary tangle (NFT) pathology and synapse loss [5]. Moreover, GVD has been reported in association with other tauopathies, such as Guam disease [21], Pick's disease, and progressive supranuclear palsy (PSP) as well as in the synucleinopathies sporadic Parkinson's disease (PD) and dementia with Lewy bodies [35]. Thus, although GVD is often referred to as an "AD-related" histopathological phenomenon it is, nevertheless, presently unclear whether it is only associated with $\mathrm{AD}$ or with other tauopathies and with synucleinopathies as well.

Recently, antibodies directed against the phosphorylated transactive-response DNA-binding protein TDP43 (pTDP43) and casein kinase 1 (CK1) isoforms $\delta$ or $\varepsilon$ have been reported to stain GVD [17, 25-27, 35]. They can be used to study GVD pathology more easily than in hematoxylin-eosin or silver stained sections.

To determine the anatomical distribution of GVD in the human brain and to clarify its relationship to dementia and $\mathrm{AD}$, we studied non-demented elderly, AD, non-AD tauopathy, sporadic PD, TDP43-proteinopathy cases for the distribution of GVD and its relationship to concomitant AD-related NFT and amyloid $\beta$-protein $(A \beta)$ pathology as well as to sporadic PD, argyrophilic grain disease (AGD), PSP, corticobasal degeneration (CBD), amyotrophic lateral sclerosis (ALS), and frontotemporal lobar degeneration (FTLD).

\section{Materials and methods}

\section{Study cohort}

A total sample of 64 autopsy cases between 59 and 98 years of age covering all stages of AD-related NFT and A $\beta$ pathology was investigated, including 14 non-demented elderly, 19 AD, 17 non AD tauopathy (9 AGD, 8 PSP or CBD), 9 PD, and 5 TDP43-proteinopathy (3 ALS and 2 FTLD) cases (Table 1). All autopsy brains were collected in accordance with local ethical committee guidelines and the federal law governing the use of human tissue in Germany and The Netherlands. Scores from the clinical dementia rating (CDR) [23] were observed retrospectively for 56 cases as previously described [42]. These data were also employed to determine whether individuals clinically met the DSM-IV criteria for dementia [2]. In three demented cases, the clinical records noted the diagnosis of dementia according to DSM-IV but did not provide sufficient information to determine the CDR score. In five non-demented cases, the clinical records did not provide sufficient information to determine the CDR score.
AD was diagnosed when dementia was observed and when the degree of AD-related neuropathology indicated at least a moderate likelihood for AD according to acknowledged criteria [45]. PD, PSP, CBD, ALS, and FTLD were diagnosed neuropathologically in the event that clinical recordings displayed respective deficits [1, 15, 18, 28, 39]. AGD was diagnosed when clinical records reported cognitive deficits, the presence of argyrophilic grains could be confirmed neuropathologically, and the amount of AD related and vascular pathology alone failed to explain dementia [24, 44].

Neuropathology and immunohistochemistry

The brains of all individuals were fixed in a $4 \%$ aqueous formaldehyde solution for at least 3 weeks before undergoing neuropathological evaluation. Tissue blocks covering the regions listed in Table 2 were excised and embedded in paraffin or polyethylene glycol (PEG; Merck-Schuchardt, Hohenbrunn, Germany). The paraffin sections were cut at $10 \mu \mathrm{m}$, whereas the PEG-blocks were sectioned at $100 \mu \mathrm{m}$.

For the detection of GVD and other neurodegenerative lesions, silver staining methods and immunohistochemistry with the primary antibodies listed in Table 3 were applied. Primary antibodies were detected with biotinylated secondary antibodies and the ABC complex (Vectastain: Vector Laboratories, Burlingame, CA, USA). This reaction was subsequently visualized with 3,3-diaminobenzidine (DAB). Immunolabeled paraffin sections were counterstained with hematoxylin. Positive and negative controls were included to confirm immunostaining results. GVD was diagnosed when multiple vacuoles (2 aggregated vacuoles or more) with granular inclusions were detected with at least one GVD-detecting antibody (Table 3). Solitary autophagic vacuoles were not considered as GVD.

To confirm co-localization of CK1 $\delta$, CK1 $1 \varepsilon$, and pTDP43 in GVD lesions, sections from the hippocampus of randomly chosen cases exhibiting GVD were used for double label immunofluorescence with anti-pTDP43 and either anti-CK $1 \delta$ or anti-CK1ع. The primary antibodies were detected with carbocyanin $\mathrm{Cy} 2$ and $\mathrm{Cy} 3$ labeled secondary antibodies. Sections were mounted in Eukitt (O. Kindler; Freiburg, Germany) and cover-slipped. All tissue sections were viewed with a Leica DMLB or an Olympus BX 51 microscope. Digital photographs were obtained with Leica cameras (DC 500 or EC3).

Diagnosis of the stages in the development of NFTs (NFT stage) and the semiquantitative assessment of neuritic plaques [Consortium to Establish a Registry for AD (CERAD) score] were performed in accordance with published and recommended criteria [7, 9, 29, 45]. For staging of $A \beta$ pathology, we used a previously published 
Table 1 List of autopsy cases studied

\begin{tabular}{|c|c|c|c|c|c|c|c|c|c|c|}
\hline Case no. & Age & Sex & Diagnosis & CDR & PD stage & NFT stage & $\mathrm{A} \beta$ phase & CERAD & CAA stage & GVD stage \\
\hline 1 & 66 & $\mathrm{f}$ & Control & 0 & n.a. & 0 & 0 & 0 & 0 & 0 \\
\hline 2 & 62 & $\mathrm{~m}$ & Control & 0 & n.a. & 0 & 0 & 0 & 0 & 0 \\
\hline 3 & 64 & $\mathrm{~m}$ & Control & 0 & n.a. & 1 & 2 & 0 & 0 & 0 \\
\hline 4 & 71 & $\mathrm{~m}$ & Control & 0 & n.a. & 1 & 3 & 0 & 0 & 0 \\
\hline 5 & 61 & $\mathrm{~m}$ & Control & 0 & n.a. & 0 & 0 & 0 & 0 & 0 \\
\hline 6 & 59 & $\mathrm{~m}$ & Control & 0 & 0 & 0 & 0 & 0 & 0 & 0 \\
\hline 7 & 71 & $\mathrm{~m}$ & Control & 0 & n.a. & 1 & 2 & 0 & 1 & 1 \\
\hline 8 & 69 & $\mathrm{f}$ & Control & 0 & n.a. & 0 & 0 & 0 & 0 & 1 \\
\hline 9 & 74 & $\mathrm{~m}$ & Control & 0 & n.a. & 1 & 0 & 0 & 0 & 2 \\
\hline 10 & 83 & $\mathrm{f}$ & Control & 0 & n.a. & 3 & 1 & 0 & 1 & 2 \\
\hline 11 & 72 & $\mathrm{~m}$ & Control & 0 & n.a. & 3 & 2 & 0 & 0 & 3 \\
\hline 12 & 83 & $\mathrm{f}$ & Control & 0 & n.a. & 4 & 3 & 1 & 2 & 3 \\
\hline 13 & 85 & $\mathrm{~m}$ & Control & 0 & n.a. & 3 & 2 & 1 & 0 & 4 \\
\hline 14 & 63 & $\mathrm{f}$ & Control & 0 & n.a. & 3 & 4 & 1 & 0 & 4 \\
\hline 15 & 73 & $\mathrm{f}$ & AGD & 0.5 & n.a. & 1 & 1 & 0 & 1 & 0 \\
\hline 16 & 81 & $\mathrm{~m}$ & AGD & 2 & n.a. & 2 & 3 & 0 & 0 & 1 \\
\hline 17 & 77 & $\mathrm{~m}$ & AGD & 0.5 & n.a. & 3 & 2 & 1 & 0 & 2 \\
\hline 18 & 88 & $\mathrm{~m}$ & AGD & 2 & n.a. & 2 & 3 & 1 & 1 & 3 \\
\hline 19 & 79 & $\mathrm{~m}$ & AGD & 2 & n.a. & 2 & 3 & 0 & 2 & 4 \\
\hline 20 & 79 & f & AGD-VD & 2 & n.a. & 2 & 0 & 0 & 0 & 4 \\
\hline 21 & 80 & f & AGD, PD & 1 & 3 & 2 & 3 & 0 & 0 & 0 \\
\hline 22 & 79 & $\mathrm{~m}$ & AGD, PD & 0 & 3 & 2 & 0 & 0 & 0 & 1 \\
\hline 23 & 75 & $\mathrm{~m}$ & AGD, PSP, PD & 2 & 4 & 3 & 2 & 0 & 1 & 0 \\
\hline 24 & 78 & $\mathrm{f}$ & CBD & 3 & n.a. & 1 & 1 & 0 & 0 & 1 \\
\hline $25^{\mathrm{a}}$ & 76 & $\mathrm{~m}$ & PSP & 0 & n.a. & 0 & 2 & 0 & 0 & 0 \\
\hline $26^{\mathrm{a}}$ & 69 & $\mathrm{f}$ & PSP & 0 & n.a. & 2 & 1 & 0 & 0 & 0 \\
\hline $27^{\mathrm{b}}$ & 59 & $\mathrm{~m}$ & PSP & n.a. & n.a. & 2 & 1 & 0 & 1 & 0 \\
\hline $28^{\mathrm{a}}$ & 81 & $\mathrm{~m}$ & PSP & 2 & n.a. & 4 & 4 & 2 & 3 & 2 \\
\hline $29^{a}$ & 76 & $\mathrm{~m}$ & PSP & 1 & n.a. & 1 & 1 & 0 & 0 & 3 \\
\hline $30^{\mathrm{b}}$ & 83 & $\mathrm{~m}$ & PSP & n.a. & n.a. & 3 & 2 & 0 & 0 & 4 \\
\hline $31^{\mathrm{a}}$ & 84 & $\mathrm{f}$ & PSP, AGD & 0 & n.a. & 0 & 0 & 0 & 1 & 0 \\
\hline 32 & 83 & f & PD & n.a. & 4 & 2 & 0 & 0 & 0 & 0 \\
\hline 33 & 69 & f & PD & n.a. & 4 & 1 & 3 & 0 & 1 & 0 \\
\hline 34 & 68 & $\mathrm{f}$ & PD & 2 & 5 & 1 & 3 & 0 & 1 & 0 \\
\hline 35 & 77 & $\mathrm{~m}$ & PD & 0 & 4 & 1 & 0 & 0 & 0 & 0 \\
\hline $36^{\mathrm{b}}$ & 76 & $\mathrm{~m}$ & PD & n.a. & 5 & 3 & 4 & 0 & 1 & 0 \\
\hline 37 & 64 & f & PD & 0 & 4 & 3 & 0 & 0 & 1 & 1 \\
\hline 38 & 68 & $\mathrm{~m}$ & PD & 0.5 & 5 & 3 & 4 & 2 & 2 & 1 \\
\hline 39 & 76 & $\mathrm{f}$ & PD & 0 & 4 & 2 & 0 & 0 & 0 & 1 \\
\hline 40 & 77 & $\mathrm{~m}$ & PD & 1 & 5 & 4 & 3 & 2 & 2 & 1 \\
\hline 41 & 68 & $\mathrm{~m}$ & ALS & 0 & n.a. & 2 & 2 & 0 & 1 & 2 \\
\hline 42 & 75 & $\mathrm{~m}$ & ALS & 0 & n.a. & 2 & 1 & 1 & 1 & 2 \\
\hline 43 & 76 & $\mathrm{f}$ & ALS & 0 & n.a. & 2 & 0 & 0 & 0 & 2 \\
\hline $44^{\mathrm{c}}$ & 76 & $\mathrm{f}$ & FTLD-TDP & 3 & n.a. & 0 & 3 & 0 & 2 & 0 \\
\hline 45 & 84 & $\mathrm{~m}$ & FTLD-TDP, AD, DLB & 3 & 6 & 6 & 4 & 3 & 2 & 5 \\
\hline 46 & 64 & $\mathrm{f}$ & $\mathrm{AD}$ & n.a. & n.a. & 6 & 4 & 3 & 1 & 1 \\
\hline 47 & 62 & $\mathrm{f}$ & $\mathrm{AD}$ & 3 & n.a. & 6 & 4 & 3 & 1 & 2 \\
\hline 48 & 72 & $\mathrm{f}$ & $\mathrm{AD}$ & 1 & n.a. & 4 & 4 & 2 & 1 & 2 \\
\hline
\end{tabular}


Table 1 continued

\begin{tabular}{|c|c|c|c|c|c|c|c|c|c|c|}
\hline Case no. & Age & Sex & Diagnosis & $\mathrm{CDR}$ & PD stage & NFT stage & $\mathrm{A} \beta$ phase & CERAD & CAA stage & GVD stage \\
\hline 49 & 86 & $\mathrm{f}$ & $\mathrm{AD}$ & 3 & n.a. & 6 & 4 & 2 & 2 & 3 \\
\hline 50 & 87 & $\mathrm{f}$ & $\mathrm{AD}$ & 3 & n.a. & 4 & 4 & 1 & 2 & 3 \\
\hline 51 & 87 & $\mathrm{f}$ & $\mathrm{AD}$ & 0.5 & n.a. & 4 & 4 & 2 & 2 & 3 \\
\hline 52 & 79 & $f$ & $\mathrm{AD}$ & n.a. & n.a. & 4 & 3 & 2 & 1 & 4 \\
\hline 53 & 82 & $\mathrm{~m}$ & $\mathrm{AD}$ & 2 & n.a. & 3 & 3 & 2 & 1 & 4 \\
\hline 54 & 89 & $\mathrm{f}$ & $\mathrm{AD}$ & 3 & n.a. & 5 & 4 & 3 & 2 & 4 \\
\hline 55 & 98 & $\mathrm{f}$ & $\mathrm{AD}$ & 2 & n.a. & 4 & 4 & 3 & 2 & 4 \\
\hline 56 & 68 & $f$ & $\mathrm{AD}$ & 1 & n.a. & 6 & 4 & 2 & 1 & 4 \\
\hline 57 & 78 & $\mathrm{~m}$ & $\mathrm{AD}$ & 3 & n.a. & 4 & 4 & 1 & 2 & 4 \\
\hline 58 & 83 & $\mathrm{f}$ & $\mathrm{AD}$ & n.a. & n.a. & 4 & 4 & 2 & 1 & 5 \\
\hline 59 & 78 & $\mathrm{~m}$ & $\mathrm{AD}$ & 1 & n.a. & 4 & 4 & 1 & 1 & 5 \\
\hline 60 & 81 & $\mathrm{f}$ & $\mathrm{AD}$ & 3 & n.a. & 5 & 4 & 1 & 1 & 5 \\
\hline 61 & 83 & $\mathrm{~m}$ & $\mathrm{AD}$ & 3 & n.a. & 5 & 4 & 2 & 3 & 5 \\
\hline 62 & 83 & $\mathrm{~m}$ & $\mathrm{AD}$ & 3 & n.a. & 4 & 4 & 3 & 2 & 5 \\
\hline 63 & 98 & f & $\mathrm{AD}$ & 0.5 & n.a. & 4 & 4 & 1 & 2 & 5 \\
\hline 64 & 78 & $\mathrm{f}$ & $\mathrm{AD}$ & 3 & n.a. & 5 & 4 & 2 & 3 & 5 \\
\hline
\end{tabular}

The table shows age in years, sex, neuropathological diagnosis, the degree of dementia (CDR score) [31], the PD stage according to Braak et al. [11], the stage of neurofibrillary tangle pathology according to Braak and Braak [9] (NFT stage), the A $\beta$ phase representing the distribution of A $\beta$ deposits in the subfields of the MTL [43], the CERAD score for the frequency of neuritic plaques according to Mirra et al. [29], the stages of CAA [40], and GVD

$m$ Male, $f$ female, (control) non-demented control, $A D$ Alzheimer's disease, $A G D$ argyrophilic grain disease, $A L S$ amyotrophic lateral sclerosis, $C B D$ corticobasal degeneration, $D L B$ dementia with Lewy bodies, FTLD-TDP frontotemporolobar degeneration with TDP43-pathology, n.a. not assessed, $P D$ Parkinson's disease, $P S P$ progressive supranuclear palsy, $V D$ vascular dementia

${ }^{a}$ Indicates cases for which brain stem and diencephalic samples were not available

${ }^{b}$ Indicates cases for which samples of the occipital lobe were not available

c Indicates cases for which samples of diencephalic regions and the parietal cortex were not available

protocol for four phases of $\beta$-amyloidosis in the MTL [43]. Cerebral amyloid angiopathy (CAA) was diagnosed whenever vascular $A \beta$ deposition was observed. The stage of the distribution of CAA-affected vessels throughout the brain was assessed according to published criteria [40, 41]. PD lesions in PD cases were staged according to previously published criteria $[1,11]$.

\section{Statistical analysis}

The presence or absence of GVD in a given brain region was assessed dichotomously with anti-pTDP43, anti-CK1 $\delta$, and/or anti-CK1ع. The brain areas listed in Table 2 were analyzed separately. Cluster analysis was performed to identify a staging pattern. The staging pattern was validated by testing the stage-related affection with GVD for each region studied with the Fisher's exact-test and subsequent trend-test. Partial correlation analysis controlled for age and gender was performed to describe the relationship between GVD stage and AD-related pathology as well as between GVD stage and the CDR score. Logistic regression analysis was performed controlling for age and gender to test whether AD was associated with the stages of GVD pathology.
Likewise, logistic regression was used to analyze the association between non-AD tauopathies (i.e., AGD, PSP, and CBD), PD, and TDP43-proteinopathies (ALS, FTLD) on the one hand and the GVD stages on the other. All statistical tests were calculated with the help of SPSSstatistical software, release 19.0 (Chicago, IL, USA). To correct for multiple testing Bonferroni correction was used.

\section{Results}

Anti-pTDP43 stained GVD similar to anti-CK1 $\delta$ and antiCK1E (Fig. 1a-c). Positively stained material lacking the typical vacuolar pattern was not considered as GVD. Double label immunofluorescence confirmed the presence of CK1 $\delta$ and CK1 $1 \varepsilon$, both antibodies co-localizing pTDP43 in GVD lesions (Fig. 1d-i). With these antibodies, a similar distribution pattern throughout all investigated brain regions was observed, thereby indicating that these methods were interchangeable for GVD staging. A regionspecific differential expression of these proteins in GVD lesions was not seen. Immunohistochemistry with the antibody against abnormal $\tau$ protein appeared less useful 
Table 2 Frequencies of GVD prevalence in the brain regions studied at each stage of GVD

\begin{tabular}{|c|c|c|c|c|c|}
\hline & GVD Stage 1 & GVD Stage 2 & GVD Stage 3 & GVD Stage 4 & GVD Stage 5 \\
\hline CA1/subiculum* & $100.00 \%$ & $100.00 \%$ & $100.00 \%$ & $100.00 \%$ & $100.00 \%$ \\
\hline entorhinal cortex (Brodmann area 28$)^{*}$ & $0.00 \%$ & $75.00 \%$ & $100.00 \%$ & $100.00 \%$ & $100.00 \%$ \\
\hline $\mathrm{CA}^{*}$ & $0.00 \%$ & $50.00 \%$ & $80.00 \%$ & $77.78 \%$ & $100.00 \%$ \\
\hline temporal cortex (Brodmann area $35 / 36)^{*}$ & $0.00 \%$ & $0.00 \%$ & $100.00 \%$ & $100.00 \%$ & $100.00 \%$ \\
\hline NBM $^{*}$ & $0.00 \%$ & $0.00 \%$ & $20.00 \%$ & $55.56 \%$ & $50.00 \%$ \\
\hline Hypothalamus* & $0.00 \%$ & $0.00 \%$ & $0.00 \%$ & $88.89 \%$ & $100.00 \%$ \\
\hline Amygdala* & $0.00 \%$ & $0.00 \%$ & $0.00 \%$ & $77.78 \%$ & $100.00 \%$ \\
\hline cingulate gyrus (Brodmann area 24)* & $0.00 \%$ & $0.00 \%$ & $0.00 \%$ & $0.00 \%$ & $75.00 \%$ \\
\hline Oral raphe/ PPTg nuclei ${ }^{*}$ & $0.00 \%$ & $0.00 \%$ & $0.00 \%$ & $0.00 \%$ & $62.50 \%$ \\
\hline Thalamus & $0.00 \%$ & $0.00 \%$ & $0.00 \%$ & $0.00 \%$ & $37.50 \%$ \\
\hline frontal cortex (Brodmann area 6) & $0.00 \%$ & $0.00 \%$ & $0.00 \%$ & $0.00 \%$ & $12.50 \%$ \\
\hline parietal cortex (Brodmann area 7) & $0.00 \%$ & $0.00 \%$ & $0.00 \%$ & $0.00 \%$ & $12.50 \%$ \\
\hline occipital cortex (Brodmann areas 17, 18, 19) & $0.00 \%$ & $0.00 \%$ & $0.00 \%$ & $0.00 \%$ & $0.00 \%$ \\
\hline basal ganglia & $0.00 \%$ & $0.00 \%$ & $0.00 \%$ & $0.00 \%$ & $0.00 \%$ \\
\hline cerebellum & $0.00 \%$ & $0.00 \%$ & $0.00 \%$ & $0.00 \%$ & $0.00 \%$ \\
\hline substantia nigra & $0.00 \%$ & $0.00 \%$ & $0.00 \%$ & $0.00 \%$ & $0.00 \%$ \\
\hline red nucleus & $0.00 \%$ & $0.00 \%$ & $0.00 \%$ & $0.00 \%$ & $0.00 \%$ \\
\hline brain stem motor neurons & $0.00 \%$ & $0.00 \%$ & $0.00 \%$ & $0.00 \%$ & $0.00 \%$ \\
\hline brain stem sensory neurons & $0.00 \%$ & $0.00 \%$ & $0.00 \%$ & $0.00 \%$ & $0.00 \%$ \\
\hline brain stem visceromotoric and -sensoric nuclei & $0.00 \%$ & $0.00 \%$ & $0.00 \%$ & $0.00 \%$ & $0.00 \%$ \\
\hline inferior olivary nucleus & $0.00 \%$ & $0.00 \%$ & $0.00 \%$ & $0.00 \%$ & $0.00 \%$ \\
\hline pontine nuclei & $0.00 \%$ & $0.00 \%$ & $0.00 \%$ & $0.00 \%$ & $0.00 \%$ \\
\hline
\end{tabular}

It is shown which percent of cases in a given GVD stage exhibit GVD lesions in a given region. For visualization the frequencies are color-coded: $0 \%$ of the cases exhibit GVD lesions = white; $1-25 \%$ of the cases exhibit GVD lesions = 20\% gray; 26-50\% of the cases exhibit GVD lesions $=40 \%$ gray; $51-75 \%$ of the cases exhibit GVD lesions $=60 \%$ gray; $76-99 \%$ of the cases exhibit GVD lesions $=80 \%$ gray; all cases exhibit GVD lesions = black

* indicates those regions that significantly showed differences in the distribution of GVD among the GVD stages (Fisher's exact-test:

$* p<0.005$ ) with a trend to increase with advancing GVD stage (trend-test: * $p<0.005$ )

Table 3 List of the conventional and immunohistochemical staining techniques used for the detection of neurodegenerative changes in this study

$\begin{array}{llllll}\text { GVD } & \text { NFT/ } & \text { Senile } & \text { Lewy } & \text { Glial } \tau & \text { TDP43 threads/ Reference/clone, distributor, dilution, pretreatment } \\ \text { NT } & \text { plaques bodies } & \text { inclusions } & \begin{array}{l}\text { NCI/Nucl. } \\ \text { inclusions }\end{array}\end{array}$

\begin{tabular}{|c|c|c|c|c|c|c|c|}
\hline Gallyas & & + & & & + & & [8] \\
\hline Campbell-Switzer & & & + & + & & & {$[8,34]$} \\
\hline $\begin{array}{l}\text { Anti-abnormal } \\
\tau \text { protein }\end{array}$ & + & + & & & + & & AT-8, Pierce-Endogen, USA, $1 / 1,000$ \\
\hline $\begin{array}{l}\text { Anti-amyloid } \beta \\
\text { protein }\end{array}$ & & & + & & & & $\begin{array}{l}\text { 4G8, Covance, Dedham, USA, 1/5,000, } \\
\text { formic acid pretreatment }\end{array}$ \\
\hline Anti- $\alpha$ synuclein & & & & + & & & $\begin{array}{l}\text { anti-syn-1; } 1: 2,000 \text {; Clone number } 42 \text {, } \\
\text { BD Biosciences, Mountain View, CA, USA }\end{array}$ \\
\hline Anti-pTDP43 & + & & & & & + & $\begin{array}{l}\text { pS409/410-2, Cosmo Bio Co., Ltd, Tokyo, Japan, } \\
\text { 1/10,000, microwave pretreatment }\end{array}$ \\
\hline Anti-CK1 $\delta$ & + & & & & & & $\begin{array}{l}108,1 \text { polyclonal rabbit, [38], 1/200, microwave } \\
\text { pretreatment }\end{array}$ \\
\hline Anti-CK1 $1 \varepsilon$ & + & & & & & & 712 polyclonal rabbit [13], 1/600, microwave pretreatment \\
\hline & & & & & & & $\begin{array}{l}\text { H-60 polycloncal rabbit, Santa Cruz Biotechnology; Santa } \\
\text { Cruz, CA, USA, 1/150, microwave pretreatment }\end{array}$ \\
\hline
\end{tabular}

The table indicates which lesions are detected with a given method. The detection of GVD with anti-abnormal phosphorylated $\tau$ antibodies is possible [16] but is less easy to analyze because other tauopathic lesions are stained as well as with this antibody

for GVD detection because this antibody also stained other $\tau$ lesions [16]. Therefore, the identification of GVD lesions was more difficult than with the other three antibodies.

The distribution of typical pTDP43- and CK1 $1 \delta / \varepsilon$-positive GVD throughout the brain regions investigated revealed a five-staged hierarchical pattern (Figs. 2, 3, 4, 5, 6; Table 2). The CA1/2-subiculum region always exhibited GVD whenever GVD was observed, regardless whether other brain regions were involved as well. Thus, GVD in the CA1/2 subiculum region in the absence of GVD elsewhere 
Fig. 1 a-c GVD lesions in the subiculum-CA1 region were detected with anti-pTDP43 (arrow in a), with anti-CK1 $\delta$ (arrow in b), and with antiCK1ع (arrow in c). Double label immunofluorescence analyses revealed co-expression of pTDP43 and CK1 $\delta$ (d-f arrows) and of pTDP43 and CK1 $1 \varepsilon$ (g-i arrows). (a, c case no. 20; b case no. 25; d-f case no. 29; $\mathbf{g - i}$ case no. 26). Calibration bar in $\mathbf{c}$ is valid for: $\mathbf{a}-\mathbf{c} 8 \mu \mathrm{m}$; d-i $13 \mu \mathrm{m}$
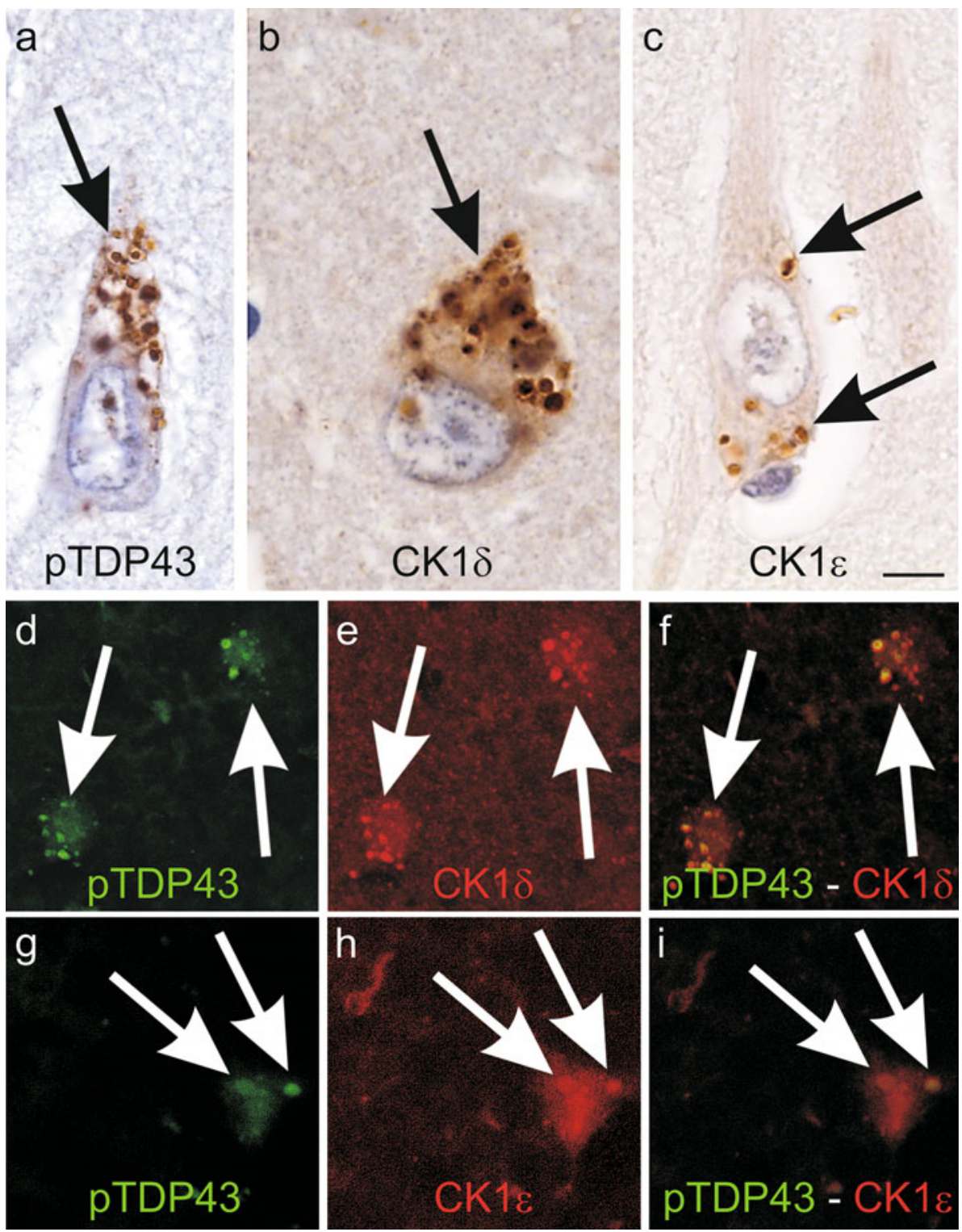

in the brain was referred to as stage 1 GVD (Fig. 2). In addition to GVD in the CA1/2 subiculum region, this pathology was also observed in the entorhinal cortex (Brodmann area 28) in neurons of layers pre- $\alpha$, pre- $\beta$, pri- $\alpha$, and pri- $\beta$ and/or in the CA4 subfield of the Ammon's horn (Table 2). GVD in CA4 can be accompanied by GVD lesions in CA3. Stage 2 GVD cases are characterized by this pathology in the absence of further GVD pathology except for occasional GVD-affected neurons in the basal nucleus of Meynert (Fig. 3; Table 2). Expansion of this pathology into layers II/III and/or $\mathrm{V}$ of the temporal neocortex (Brodmann areas 35 and 36) (Table 2) was referred to as GVD stage 3 (Fig. 4). In GVD stage 4, GVD-containing neurons were also observed in the amygdala (amygdalohippocampal area, amygdalo-piriform area, central amygdaloid nucleus, basolateral and basomedial nuclear complexes) and/or in hypothalamic neurons of the tuberomammillary, paraventricular, supraoptic, ventromedial, dorsomedian, medial mammillary nuclei and/or nuclei of the anterior and lateral hypothalamic area (Fig. 5; Table 2). In the final stage, GVD stage 5, GVD was observed in layers II/III and V neurons of the cingulate gyrus (area 24) as well as in the oral raphe nuclei, the pedunculopontine tegmental nucleus, the superficial and medial thalamic nuclei. Occasionally, GVD lesions were also found in the frontal (Brodmann area 6) and parietal neocortex (Brodmann area 7) (Fig. 6; Table 2). As indicated in Table 2, the presence or absence of GVD in given brain regions resulted in significant differences among the GVD stages. The trend-test confirmed the hierarchical involvement of more and more brain regions (Table 2).

With advancing GVD stage, an increase was also noted in the NFT stage, the CERAD score for neuritic plaques, the phase of $A \beta$ deposition in the MTL, the CAA stage, and 
Fig. 2 GVD stage 1: GVDaffected neurons (marked in red) were limited to the CA1subiculum regions (arrows). The right diagram depicts the forebrain hemisphere at the level of the entorhinal region and the hypothalamus, the left shows a section at the level of the lateral geniculate body and the substantia nigra. Anatomical orientation: Amy amygdala, $\mathrm{Bgl}$ basal ganglia, incl. Caudate nucleus, putamen and globus pallidus, $C A 1 \mathrm{CA} 1 /$ subiculum sector of the hippocampus, CA4 CA4 sector of the hippocampus, cing cingulate gyrus, $E R$ entorhinal cortex, $F$ frontal cortex, Hypoth hypothalamus, $M B$ midbrain, $N B M$ basal nucleus of Meynert, $T$ temporal cortex, Thal thalamus

Fig. 3 GVD stage 2: In addition to neurons affected in GVD stage 1 entorhinal and CA4 neurons exhibited GVD as well (arrows). GVD-affected neurons are marked in red. Basal nucleus of Meynert neurons only occasionally exhibited GVD-affected neurons and were, therefore, not included in this schematic representation because this region was not relevant for staging
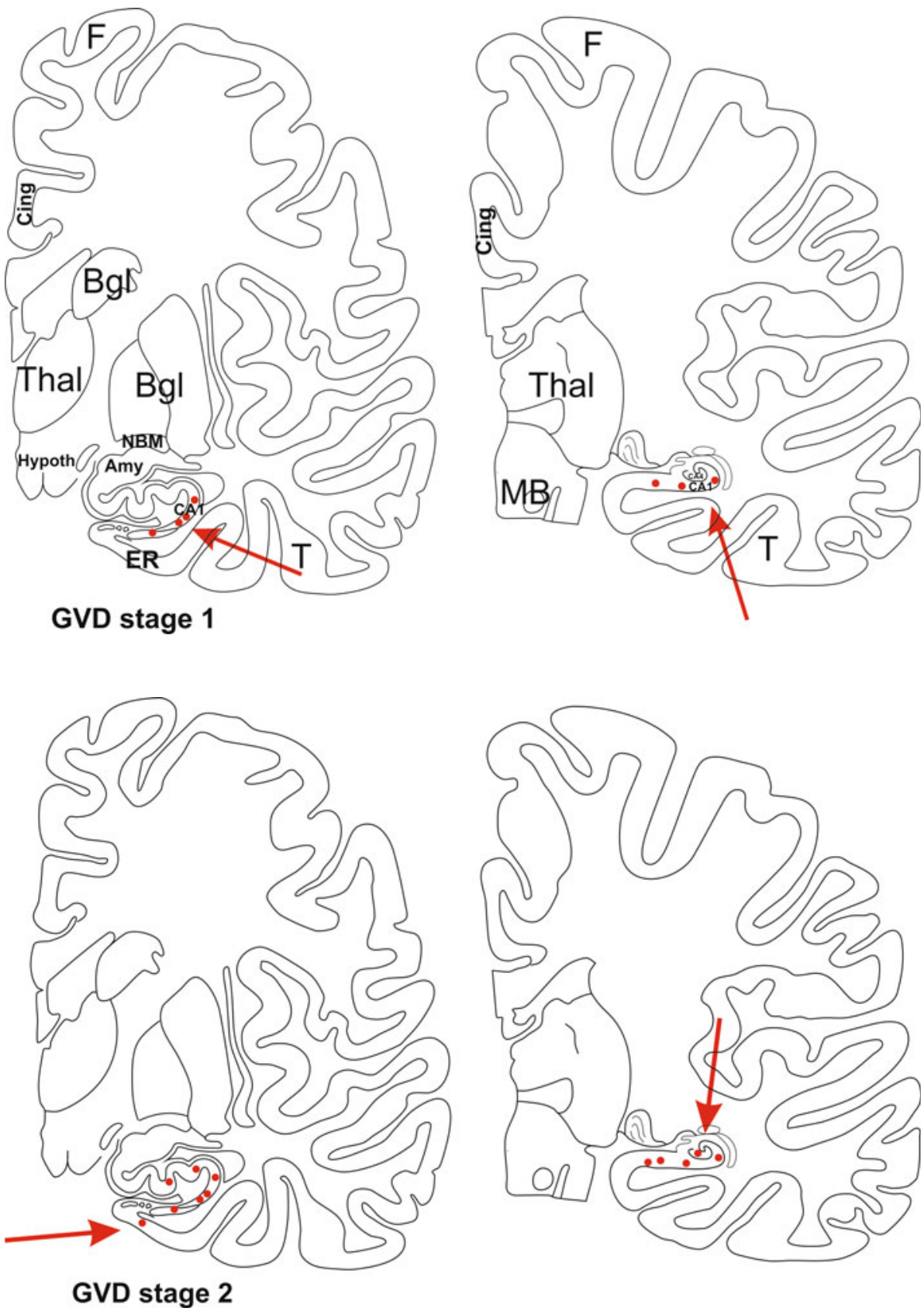

the degree of dementia as represented by the CDR score (Fig. 7a). GVD stage correlated with the NFT stage (partial correlation coefficient for age and gender: $r=0.624, p<$ 0.002 ), with the CERAD neuritic plaque score (partial correlation coefficient for age and gender: $r=0.526, p<$ $0.002)$, the $\mathrm{A} \beta$ phase for plaque deposition in the MTL (partial correlation coefficient for age and gender: $r=$ $0.454, p<0.002$ ), CAA stage (partial correlation coefficient for age and gender: $r=0.298, p=0.038$ ), and the CDR score for dementia (Partial correlation coefficient for age and gender: $r=0.347, p=0.020$ ) (Fig. 7a). After exclusion of the AD cases, there was still a correlation with
NFT stage (partial correlation coefficient for age and gender: $r=0.462, p=0.006$ ) in the group of all non-AD cases whereas no significant correlation was observed for CERAD neuritic plaque score $(p=0.053), \mathrm{A} \beta$ phase $(p=0.711)$, CAA stage $(p=0.999)$, and CDR score $(p=0.946)$.

Finally, logistic regression analysis controlled for age and gender revealed an association of AD with the GVD stage (Fig. 7b; odds ratio $=2.741,95 \%$ CI: $1.59-4.724$, $p<0.004)$. After exclusion of the AD cases, non-AD tauopathies (AGD, PSP and CBD), sporadic PD and TDP43-proteinopathies (ALS/FTLD) were not associated with the GVD stage in our sample (Fig. 7c; non-AD 
Fig. 4 GVD stage 3: Further GVD-affected neurons (marked in red) in addition to those already showing GVD in stage 2 were found in the temporal neocortex (area 36) (arrows). Basal nucleus of Meynert neurons only occasionally exhibited GVD-affected neurons and were, therefore, not included in this schematic representation because this region was not relevant for staging
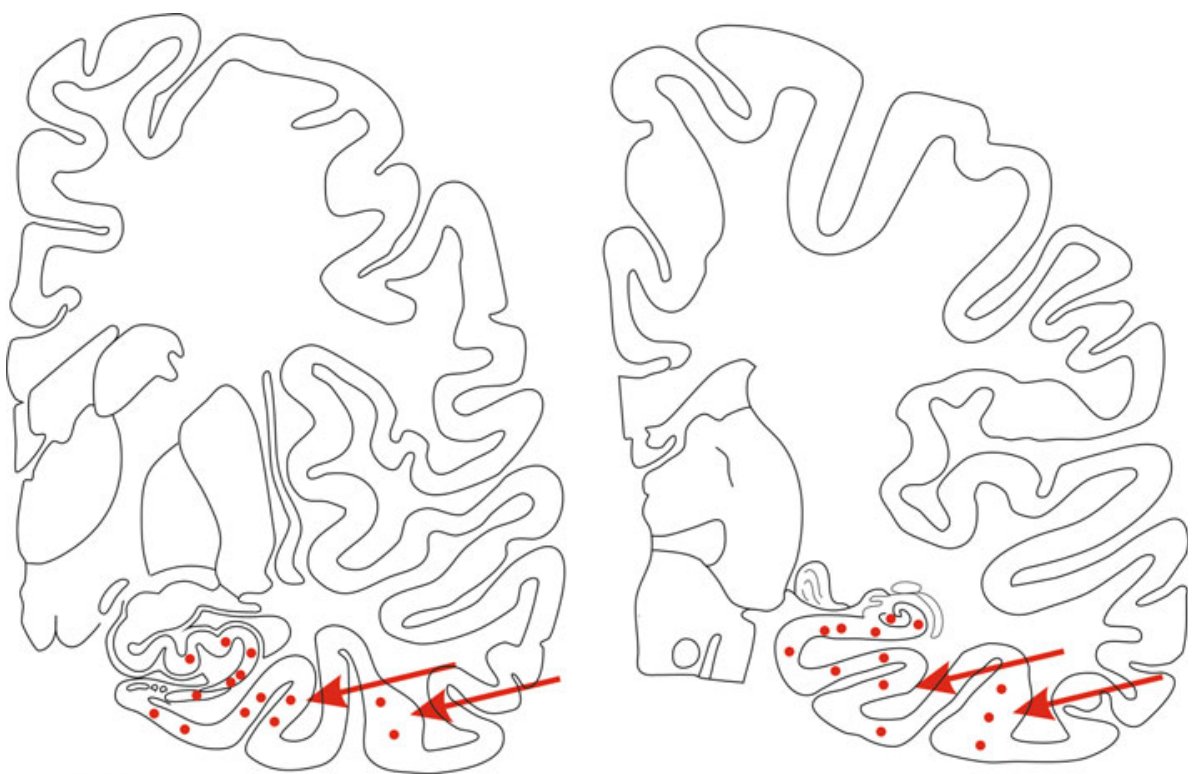

\section{GVD stage 3}
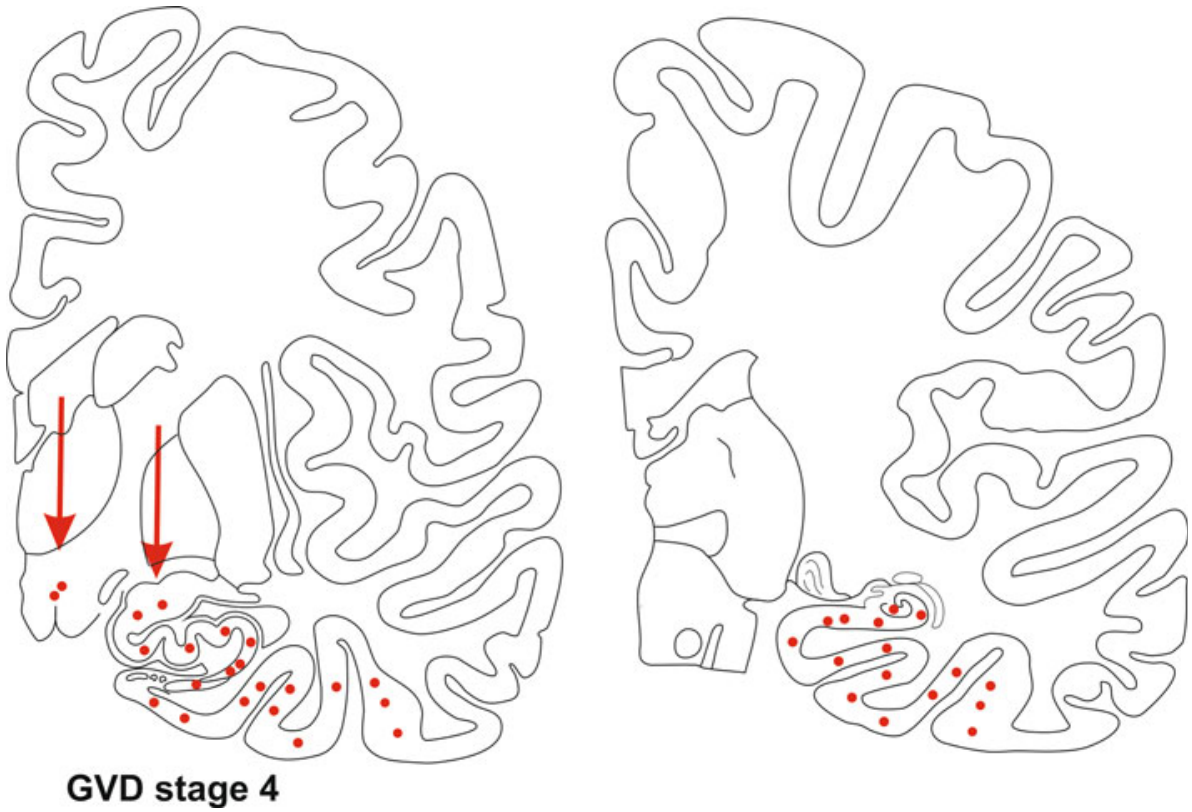

GVD stage 4

Fig. 5 GVD stage 4: GVDaffected neurons (marked in red) were found in the amygdala and in the hypothalamus (arrows) in addition to those in areas already affected in stage 3 . Basal nucleus of Meynert neurons only occasionally exhibited GVD-affected neurons and were, therefore, not included in this schematic representation because this region was not relevant for staging

tauopathies: $p=0.473$; PD: $p=0.186$; TDP43-proteinopathies: $p=0.989$ ).

\section{Discussion}

Here, we show that GVD represents a pathological lesion in the brain that first develops in neurons of the CA1/2subiculum region and, thereafter, expands in a predictable sequence into neurons of additional brain regions. This hierarchical distribution pattern makes it possible to distinguish five GVD stages (Figs. 2, 3, 4, 5, 6):
Stage 1 GVD occurs only in the CA1/2-subiculum region.

Stage 2 GVD is found in the CA1/2-subiculum region, and additionally in the entorhinal cortex and/or CA4; CA3, and the basal nucleus of Meynert can occasionally exhibit GVD-affected neurons in this stage.

Stage 3 Stage 2 regions and the temporal neocortex display the presence of GVD.

Stage 4 GVD is localized in stage 3 regions, subnuclei of the amygdala, and/or the hypothalamus. 
Fig. 6 GVD stage 5: The final stage of GVD distribution showed GVD-affected neurons (marked in red) in the cingulate gyrus, other neocortical regions, the thalamus and the raphe nuclei and/or the pedunculopontine tegmental nucleus (PPTg; arrows).

Neurons of the basal nucleus of Meynert were also affected
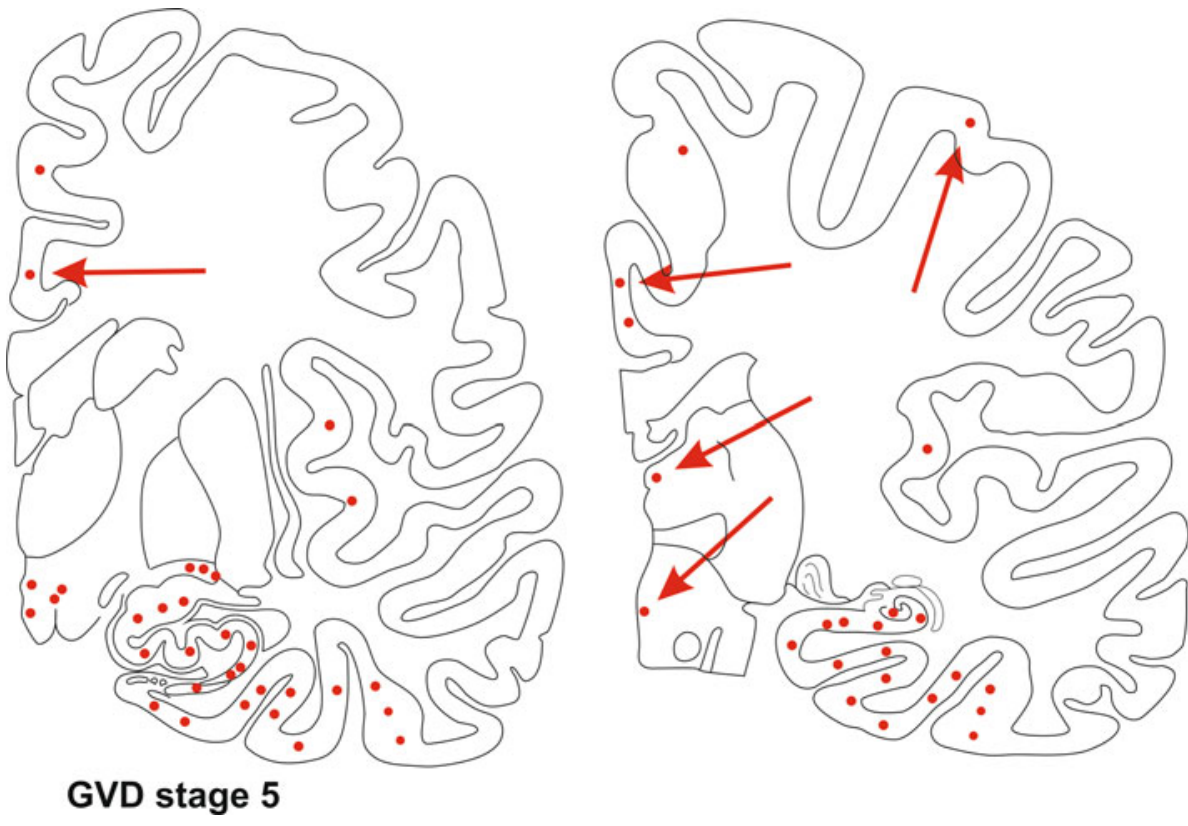

Stage 5 GVD is seen in the CA1/2-subiculum region, entorhinal cortex, CA4, temporal neocortex, subnuclei of the amygdala and the hypothalamus, oral raphe nuclei, pedunculopontine tegmental nucleus, cingulate gyrus, and occasionally in the superficial and medial nuclei of the thalamus, frontal and parietal neocortex.

This staging system confirms the findings of earlier studies that the CA1/2-subiculum region is a predilection site for GVD [4, 49] and, as reported by other groups [4, 37, 49, 50], that GVD, when present, occurs in the hippocampus, entorhinal, temporal and cingulate gyrus, hypothalamus, and amygdala. However, we also found GVD at additional sites, including the oral raphe nuclei, the pedunculopontine tegmental nucleus, superficial and medial thalamic nuclei, the basal nucleus of Meynert, and occasionally in other neocortical areas, whereby the visual cortex (Brodmann areas 17-19) appeared to be spared. The overall distribution pattern of GVD in our study corresponds to that described by other authors [50] and, as shown here, it also correlates with the distribution pattern of AD-related NFTs (NFT stage), A $\beta$ plaques (A $\beta$ phase), neuritic plaques (CERAD neuritic plaque score), CAA (CAA stage), and with the degree of dementia (CDR score). This correlation was not explained by age and gender effects since partial correlation analysis was appropriately controlled for age and gender. As such, it appears more than likely that GVD represents a fourth pathological hallmark of $\mathrm{AD}$ in addition to NFTs, A $\beta$ plaques and CAA.

Other neurodegenerative diseases such as PD, non-AD tauopathies (including AGD, PSP, CBD), and TPD43- proteinopathies, such as ALS/FTLD were not associated with increased GVD stages although GVD (mean GVD stage 1.29; range $0-5$ ) was observed in $42-80 \%$ of these cases similar to age-matched controls. Logistic regression models controlled for age and gender confirmed the association of GVD stage with AD. Therefore, the expansion of GVD pathology in its end stage distribution pattern appears to be AD related. An argument against this hypothesis is that GVD also occurs in up to $80 \%$ of cases with PSP, AGD, PD, ALS, and FTLD-TDP43. The extent, however, of the GVD lesions throughout the brain most frequently corresponded to early GVD stages, which could just as easily be explained by the presence of concomitant ADrelated pathology in these cases. Since nearly all individuals who died at the age of 40 years or older have been shown to exhibit at least minimal AD-like $\tau$ pathology in the brain stem [12] we were unable to find a single "pure" GVD case in the absence of early $\tau$ lesions. These latest results may provide additional evidence in favor of a link between GVD and AD. Another argument against GVD as an AD-related pathology is that vacuolar lesions in ballooned neurons have been described previously as GVD in a familial PD case [30]. Nonetheless, this study did not take into account that $\mathrm{CK} 1 \delta$ and $\mathrm{CK} 1 \varepsilon$ failed to stain GVD within ballooned neurons in our CBD and AGD cases as well as in the sample reported by Schwab et al. [35]. Because we did not study Pick disease cases we cannot exclude an association of this disorder with the extent of GVD-affected neurons as represented by the GVD stage similar to that seen in AD cases.

When comparing studies about GVD it seems to be of major importance to compare the determination of GVD 

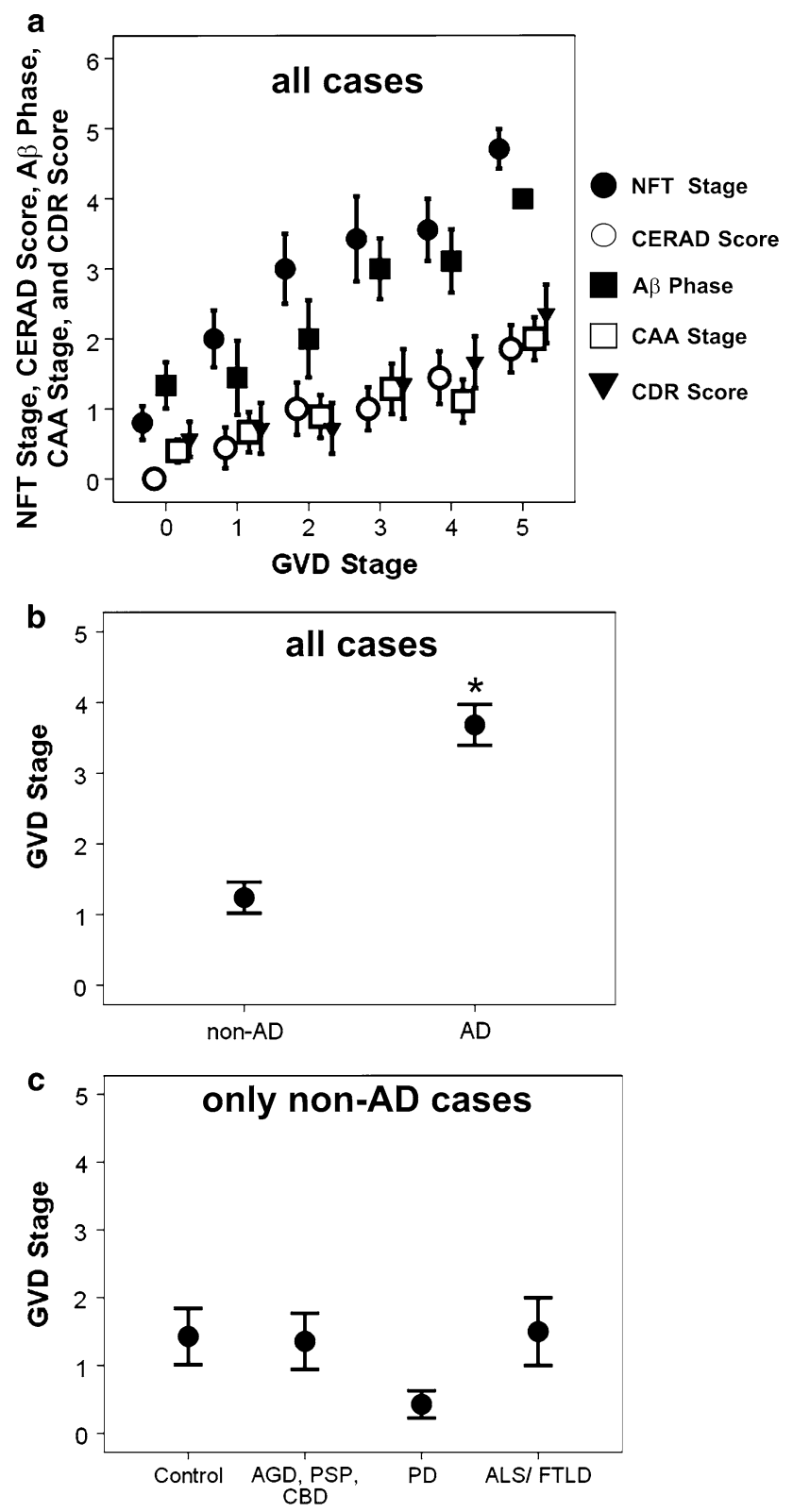

Fig. 7 a Relationship between GVD stage and neurofibrillary pathology (NFT stage), neuritic plaque pathology (CERAD score), $\mathrm{A} \beta$ pathology ( $A \beta$ phase), CAA (CAA stage), and the degree of dementia as represented by the CDR score. The increase of the GVD stage correlated with that of NFT stage, CERAD score, A $\beta$ phase, CAA stage, and the degree of dementia as represented by the CDR score (partial correlation analysis controlled for ages and sex: $r=0.33-0.624 ; p<0.05)$. b AD cases exhibited higher GVD stages than non-AD controls $(* p<0.004)$. c After exclusion of the AD cases non-AD tauopathy cases (covering AGD, PSP, and CBD), PD cases and TDP43-proteinopathy cases (covering ALS and FTLD-TDP) did not exhibit higher GVD stages than controls

used by the authors. Here, we determined GVD as pTDP43-, CK1 $\delta$ - and CK1 $1 \varepsilon$-positive accumulations of at least two aggregated vacuoles containing granular inclusions. We considered solitary vacuoles as autophagic vacuoles but not as GVD even when they were stained.

The stages of GVD proposed here describe the biological process of a hierarchical expansion of this pathology throughout the brain. As such, the GVD stages describe a parameter that is related to the severity of GVD and independently of neuronal loss, which decreases, e.g., the number of CA1 neurons exhibiting GVD, in end-stage AD cases. Since $A \beta$ and $\tau$ targeting treatment strategies against $\mathrm{AD}$ have been unsuccessful to date [22, 32, 48] GVD presumably will be important for the understanding of ADrelated pathomechanisms as well as for the identification of alternative therapeutic targets. In contrast to this potential scientific relevance of GVD and GVD stages, GVD does not contribute to the clinical and neuropathological diagnosis of $\mathrm{AD}$ in addition to $\tau$ and $\mathrm{A} \beta$ pathology. Therefore, although we do not recommend staging or even diagnosis of GVD lesions for routine neuropathological use, we do recommend it as a parameter for neuropathological studies of neurodegenerative disorders as well as for brain banking purposes. Especially when studying NFT pathology, e.g., within the context of $\mathrm{AD}$, biochemical analysis cannot distinguish between $\tau$ protein derived from NFTs and $\tau$ protein derived from GVD. Therefore, it is necessary to focus on regions with NFT-only pathology, i.e. regions that do not exhibit GVD when analyzing NFT-related $\tau$ pathology.

GVD is not directly linked to NFT pathology or A $\beta$ plaque deposition. Two 62-year-old $\mathrm{AD}$ cases from our sample with NFT stage VI, A $\beta$-phase 4 but only GVD stages 1 and 2, respectively, support this hypothesis. A non-demented control case (No. 14) exhibiting GVD stage 4 , NFT stage III, and A $\beta$ phase 4 demonstrates, on the other hand, that GVD, NFT, and A $\beta$ pathology alone do not explain dementia, as seen in AD case No. 53 with GVD stage 4 , NFT stage III, and A $\beta$ phase 3 . Here, the presence or absence of CAA might explain dementia. Thus, GVD itself accounts for the development of late-onset $\mathrm{AD}$, although other factors, such as age of onset, genetic background, NFTs, and parenchymal and vascular A $\beta$ pathology, significantly contribute as well. It needs to be clarified in the future whether GVD distinguishes specific types of $\mathrm{AD}$ or represents a late-onset $\mathrm{AD}$ phenomenon. An argument favoring the latter hypothesis is the finding of Ball et al. [5] that GVD does not play a role in Down syndrome cases even when they show severe neurofibrillary pathology.

Neurons exhibiting GVD lesions in our study occurred in regions involved in response to chronic stress [47] and in the modulation of the sleep-wakefulness state [33]. GVD involved neurons of the top-down regulation circuit of the autonomic response to chronic stress, i.e., the hippocampus (CA1, CA2, CA4, subiculum), entorhinal cortex with 
adjacent temporal cortex, cingulate gyrus, prefrontal cortex, amygdala, and hypothalamus. Each of these regions receives input from the locus coeruleus which is a major wakefulness-promoting nucleus $[6,33]$ that becomes activated in response to chronic stressors [47]. A central role for the locus coeruleus in the pathogenesis of $\mathrm{AD}$ has been discussed recently because this nucleus exhibits $\tau$ pathology very early in life [10, 12] and its degeneration has been shown to promote the development of AD-related lesions in experimental animal models of AD [19, 20]. Thus, one may speculate that chronically stressful influences and disturbed sleep-wakefulness modulation may play a role in the pathogenesis of AD. GVD appears to represent a morphological correlative for the alteration of nerve cells owing to chronic stress response. Further studies are required to verify this hypothesis. Single cell analysis of GVD-affected neurons as well as detection of chronic stress-induced inflammatory response may help to clarify this issue.

In summary, we show here that GVD lesions extend into increasing numbers of brain regions in an ordered sequence that allows the distinction of five stages. In this process, the expansion of GVD lesions correlates with the distribution of AD-related neuropathological lesions but not with other tauopathies (PSP, AGD, CBD), sporadic PD, and TDP43proteinopathies (ALS/FTLD-TDP)—an indication that GVD is associated with AD but not with neurodegeneration in general. In addition, the anatomical distribution pattern of GVD in the brain corresponds to regions involved in chronic stress response and in sleep-wakefulness modulation. Taken together, these points permit us to hypothesize that GVD anatomically related to chronic stress and its processing by the brain may contribute to the development of $\mathrm{AD}$ as a fourth factor in addition to the intraneuronal aggregation of $\tau$ protein, $A \beta$ deposition in senile plaques, and CAA.

Acknowledgments The authors gratefully acknowledge the assistance of Mrs. Irina Lungrin (immunohistochemistry). They also thank Dr. Peter Müller (Offenbach am Main; Germany), the Braak Collection (Frankfurt am Main, Germany) and Dr. Rob de Vos (Enschede; The Netherlands) for providing autopsy material. Dietmar R. Thal, Heiko Braak and Kelly Del Tredici received research grants from the Deutsche Forschungsgemeinschaft (DFG TH624/6-1 (DRT), TR1000/1-1 (KDT)), the Michael J. Fox Foundation for Parkinson's research (New York City, NY, USA (HB and KDT)), and the Alzheimer Forschung Initiative (\#10810 (DRT)).

\section{References}

1. Alafuzoff I, Ince PG, Arzberger T, Al-Sarraj S, Bell J, Bodi I, Bogdanovic N, Bugiani O, Ferrer I, Gelpi E, Gentleman S, Giaccone G, Ironside JW, Kavantzas N, King A, Korkolopoulou P, Kovacs GG, Meyronet D, Monoranu C, Parchi P, Parkkinen L, Patsouris E, Roggendorf W, Rozemuller A, Stadelmann-Nessler
C, Streichenberger N, Thal DR, Kretzschmar H (2009) Staging/ typing of Lewy body related alpha-synuclein pathology: a study of the BrainNet Europe Consortium. Acta Neuropathol 117:635652

2. American Psychiatric Association (1994) Diagnostic and statistical manual of mental disorders. Washington, DC

3. Ball MJ (1977) Neuronal loss, neurofibrillary tangles and granulovacuolar degeneration in the hippocampus with ageing and dementia. A quantitative study. Acta Neuropathol (Berl) 37:111-118

4. Ball MJ, Lo P (1977) Granulovacuolar degeneration in the ageing brain and in dementia. J Neuropathol Exp Neurol 36:474-487

5. Ball MJ, Nuttall K (1980) Neurofibrillary tangles, granulovacuolar degeneration, and neuron loss in Down Syndrome: quantitative comparison with Alzheimer dementia. Ann Neurol 7:462-465

6. Berridge CW, Waterhouse BD (2003) The locus coeruleus-noradrenergic system: modulation of behavioral state and statedependent cognitive processes. Brain Res Brain Res Rev 42:33-84

7. Braak H, Alafuzoff I, Arzberger T, Kretzschmar H, Del Tredici K (2006) Staging of Alzheimer disease-associated neurofibrillary pathology using paraffin sections and immunocytochemistry. Acta Neuropathol 112:389-404

8. Braak H, Braak E (1991) Demonstration of amyloid deposits and neurofibrillary changes in whole brain sections. Brain Pathol $1: 213-216$

9. Braak H, Braak E (1991) Neuropathological stageing of Alzheimer-related changes. Acta Neuropathol 82:239-259

10. Braak H, Del Tredici K (2011) The pathological process underlying Alzheimer's disease in individuals under thirty. Acta Neuropathol 121:171-181

11. Braak H, Del Tredici K, Rub U, de Vos RA, Jansen Steur EN, Braak E (2003) Staging of brain pathology related to sporadic Parkinson's disease. Neurobiol Aging 24:197-211

12. Braak H, Thal DR, Ghebremedhin E, Del Tredici K Stages of the pathological process in Alzheimer's disease: age categories 1 year to 100 years. J Neuropathol Exp Neurol (in press)

13. Brockschmidt C, Hirner H, Huber N, Eismann T, Hillenbrand A, Giamas G, Radunsky B, Ammerpohl O, Bohm B, Henne-Bruns D, Kalthoff H, Leithauser F, Trauzold A, Knippschild U (2008) Anti-apoptotic and growth-stimulatory functions of CK1 delta and epsilon in ductal adenocarcinoma of the pancreas are inhibited by IC261 in vitro and in vivo. Gut 57:799-806

14. Dakson A, Yokota O, Esiri M, Bigio EH, Horan M, Pendleton N, Richardson A, Neary D, Snowden JS, Robinson A, Davidson YS, Mann DM (2011) Granular expression of prolyl-peptidyl isomerase PIN1 is a constant and specific feature of Alzheimer's disease pathology and is independent of tau, Abeta and TDP-43 pathology. Acta Neuropathol 121:635-649

15. Dickson D, Litvan I (2003) Corticobasal degeneration. In: Dickson DW (ed) Neurodegeneration: the molecular pathology of dementia and movement disorders. ISN Neuropath Press, Basel, pp 115-123

16. Dickson DW, Ksiezak-Reding H, Davies P, Yen SH (1987) A monoclonal antibody that recognizes a phosphorylated epitope in Alzheimer neurofibrillary tangles, neurofilaments and tau proteins immunostains granulovacuolar degeneration. Acta Neuropathol 73:254-258

17. Ghoshal N, Smiley JF, DeMaggio AJ, Hoekstra MF, Cochran EJ, Binder LI, Kuret J (1999) A new molecular link between the fibrillar and granulovacuolar lesions of Alzheimer's disease. Am J Pathol 155:1163-1172

18. Hauw JJ, Agid Y (2003) Progressive supranuclear palsy (PSP) or Steele-Richardson-Olzewski disease. In: Dickson DW (ed) Neurodegeneration: the molecular pathology of dementia and movement disorders. ISN Neuropath Press, Basel, pp 103-114 
19. Heneka MT, Nadrigny F, Regen T, Martinez-Hernandez A, Dumitrescu-Ozimek L, Terwel D, Jardanhazi-Kurutz D, Walter J, Kirchhoff F, Hanisch UK, Kummer MP (2010) Locus ceruleus controls Alzheimer's disease pathology by modulating microglial functions through norepinephrine. Proc Natl Acad Sci USA 107:6058-6063

20. Heneka MT, Ramanathan M, Jacobs AH, Dumitrescu-Ozimek L, Bilkei-Gorzo A, Debeir T, Sastre M, Galldiks N, Zimmer A, Hoehn M, Heiss WD, Klockgether T, Staufenbiel M (2006) Locus ceruleus degeneration promotes Alzheimer pathogenesis in amyloid precursor protein 23 transgenic mice. J Neurosci 26:1343-1354

21. Hirano A, Dembitzer HM, Kurland LT, Zimmerman HM (1968) The fine structure of some intraganglionic alterations. Neurofibrillary tangles, granulovacuolar bodies and "rod-like" structures as seen in Guam amyotrophic lateral sclerosis and parkinsonismdementia complex. J Neuropathol Exp Neurol 27:167-182

22. Holmes C, Boche D, Wilkinson D, Yadegarfar G, Hopkins V, Bayer A, Jones RW, Bullock R, Love S, Neal JW, Zotova E, Nicoll JA (2008) Long-term effects of Abeta42 immunisation in Alzheimer's disease: follow-up of a randomised, placebo-controlled phase I trial. Lancet 372:216-223

23. Hughes CP, Berg L, Danziger WL, Coben LA, Martin RL (1982) A new clinical scale for the staging of dementia. Br J Psychiatry 140:566-572

24. Josephs KA, Whitwell JL, Parisi JE, Knopman DS, Boeve BF, Geda YE, Jack CR Jr, Petersen RC, Dickson DW (2008) Argyrophilic grains: a distinct disease or an additive pathology? Neurobiol Aging 29:566-573

25. Kadokura A, Yamazaki T, Kakuda S, Makioka K, Lemere CA, Fujita Y, Takatama M, Okamoto K (2009) Phosphorylationdependent TDP-43 antibody detects intraneuronal dot-like structures showing morphological characters of granulovacuolar degeneration. Neurosci Lett 463:87-92

26. Kannanayakal TJ, Tao H, Vandre DD, Kuret J (2006) Casein kinase1 isoforms differentially associate with neurofibrillary and granulovacuolar degeneration lesions. Acta Neuropathol 111:413-421

27. Lippa CF, Rosso AL, Stutzbach LD, Neumann M, Lee VM, Trojanowski JQ (2009) Transactive response DNA-binding protein 43 burden in familial Alzheimer disease and Down syndrome. Arch Neurol 66:1483-1488

28. Mackenzie IR, Neumann M, Bigio EH, Cairns NJ, Alafuzoff I, Kril J, Kovacs GG, Ghetti B, Halliday G, Holm IE, Ince PG, Kamphorst W, Revesz T, Rozemuller AJ, Kumar-Singh S, Akiyama H, Baborie A, Spina S, Dickson DW, Trojanowski JQ, Mann DM (2010) Nomenclature and nosology for neuropathologic subtypes of frontotemporal lobar degeneration: an update. Acta Neuropathol 119:1-4

29. Mirra SS, Heyman A, McKeel D, Sumi SM, Crain BJ, Brownlee LM, Vogel FS, Hughes JP, van Belle G, Berg L (1991) The Consortium to Establish a Registry for Alzheimer's Disease (CERAD). Part II. Standardization of the neuropathologic assessment of Alzheimer's disease. Neurology 41:479-486

30. Mizutani T, Inose T, Nakajima S, Kakimi S, Uchigata M, Ikeda K, Gambetti P, Takasu T (1998) Familial parkinsonism and dementia with ballooned neurons, argyrophilic neuronal inclusions, atypical neurofibrillary tangles, tau-negative astrocytic fibrillary tangles, and Lewy bodies. Acta Neuropathol 95:15-27

31. Morris JC, Heyman A, Mohs RC, Hughes JP, van Belle G, Fillenbaum G, Mellits ED, Clark C (1989) The Consortium to Establish a Registry for Alzheimer's Disease (CERAD). Part I. Clinical and neuropsychological assessment of Alzheimer's disease. Neurology 39:1159-1165

32. Nicoll JA, Wilkinson D, Holmes C, Steart P, Markham H, Weller RO (2003) Neuropathology of human Alzheimer disease after immunization with amyloid-beta peptide: a case report. Nat Med 9:448-452

33. Samuels ER, Szabadi E (2008) Functional neuroanatomy of the noradrenergic locus coeruleus: its roles in the regulation of arousal and autonomic function part I: principles of functional organisation. Curr Neuropharmacol 6:235-253

34. Sandmann-Keil D, Braak H, Okochi M, Haass C, Braak E (1999) Alpha-synuclein immunoreactive Lewy bodies and Lewy neurites in Parkinson's disease are detectable by an advanced silverstaining technique. Acta Neuropathol 98:461-464

35. Schwab C, DeMaggio AJ, Ghoshal N, Binder LI, Kuret J, McGeer PL (2000) Casein kinase 1 delta is associated with pathological accumulation of tau in several neurodegenerative diseases. Neurobiol Aging 21:503-510

36. Simchowicz T (1911) Histopathologische Studien über die senile Demenz. In: Nissl F, Alzheimer A (eds) Histologie und histopathologische Arbeiten über die Großhirnrinde. Fischer, Jena, pp 267-444

37. Steele JC, Richardson JC, Olszewski J (1964) Progressive Supranuclear Palsy. A heterogeneous degeneration involving the brain stem, basal ganglia and cerebellum with vertical gaze and pseudobulbar palsy, nuchal dystonia and dementia. Arch Neurol 10:333-359

38. Stoter M, Bamberger AM, Aslan B, Kurth M, Speidel D, Loning T, Frank HG, Kaufmann P, Lohler J, Henne-Bruns D, Deppert W, Knippschild U (2005) Inhibition of casein kinase I delta alters mitotic spindle formation and induces apoptosis in trophoblast cells. Oncogene 24:7964-7975

39. Strong MJ, Grace GM, Freedman M, Lomen-Hoerth C, Woolley S, Goldstein LH, Murphy J, Shoesmith C, Rosenfeld J, Leigh PN, Bruijn L, Ince P, Figlewicz D (2009) Consensus criteria for the diagnosis of frontotemporal cognitive and behavioural syndromes in amyotrophic lateral sclerosis. Amyotroph Lateral Scler 10:131-146

40. Thal DR, Ghebremedhin E, Orantes M, Wiestler OD (2003) Vascular pathology in Alzheimer's disease: correlation of cerebral amyloid angiopathy and arteriosclerosis/lipohyalinosis with cognitive decline. J Neuropathol Exp Neurol 62:1287-1301

41. Thal DR, Griffin WST, De Vos RAI, Ghebremedhin E (2008) Cerebral amyloid angiopathy and its relationship to Alzheimer's disease. Acta Neuropathol 115:599-609

42. Thal DR, Papassotiropoulos A, Saido TC, Griffin WS, Mrak RE, Kölsch H, Del Tredici K, Attems J, Ghebremedhin E (2010) Capillary cerebral amyloid angiopathy identifies a distinct APOE epsilon4-associated subtype of sporadic Alzheimer's disease. Acta Neuropathol 120:169-183

43. Thal DR, Rüb U, Schultz C, Sassin I, Ghebremedhin E, Del Tredici K, Braak E, Braak H (2000) Sequence of Abeta-protein deposition in the human medial temporal lobe. J Neuropathol Exp Neurol 59:733-748

44. Thal DR, Schultz C, Botez G, Del Tredici K, Mrak RE, Griffin WS, Wiestler OD, Braak H, Ghebremedhin E (2005) The impact of argyrophilic grain disease on the development of dementia and its relationship to concurrent Alzheimer's disease-related pathology. Neuropathol Appl Neurobiol 31:270-279

45. The National Institute on Aging (1997) Consensus recommendations for the postmortem diagnosis of Alzheimer's disease. The National Institute on Aging, and Reagan Institute Working Group on Diagnostic Criteria for the Neuropathological Assessment of Alzheimer's Disease. Neurobiol Aging 18:S1-S2

46. Tomlinson BE, Kitchener D (1972) Granulovacuolar degeneration of hippocampal pyramidal cells. J Pathol 106:165-185

47. Ulrich-Lai YM, Herman JP (2009) Neural regulation of endocrine and autonomic stress responses. Nat Rev Neurosci 10:397-409 
48. van Bebber F, Paquet D, Hruscha A, Schmid B, Haass C (2010) Methylene blue fails to inhibit Tau and polyglutamine protein dependent toxicity in zebrafish. Neurobiol Dis 39:265-271

49. Woodard JS (1962) Clinicopathologic significance of granulovacuolar degeneration in Alzheimer's disease. J Neuropathol Exp Neurol 21:85-91
50. Yamazaki Y, Takahashi T, Hiji M, Kurashige T, Izumi Y, Yamawaki T, Matsumoto M (2010) Immunopositivity for ESCRT-III subunit CHMP2B in granulovacuolar degeneration of neurons in the Alzheimer's disease hippocampus. Neurosci Lett 477:86-90 